\title{
SUNCT syndrome responding absolutely to steroids in two cases with different etiologies
}

\author{
María de Lourdes Figuerola • Osvaldo Bruera • \\ María Josefina Pozzo $\cdot$ Jorge Leston
}

Received: 16 September 2008/Accepted: 17 October 2008/Published online: 20 November 2008

(c) Springer-Verlag 2008

\begin{abstract}
SUNCT is a syndrome of short-lasting unilateral neuralgiform headache attacks with conjunctival injection and tearing. We are presenting now two cases absolutely responders to steroid therapy, one of them a SUNCT-like secondary to a prolactinoma and the other primary.
\end{abstract}

Keywords SUNCT $\cdot$ Steroids $\cdot$ Prolactinoma

\section{Introduction}

SUNCT is a syndrome of short-lasting unilateral neuralgiform headache attacks with conjunctival injection and tearing. It was first described in 1978 and fully characterized in 1989 [1, 2].

Suggested criteria for its diagnosis include attacks of unilateral, moderately severe orbital or temporal stabbing or throbbing pain lasting 5-240 s, with an attack frequency of 3-200 per day and pain is associated with important

M. de Lourdes Figuerola

CEDIE, CONICET, Hospital de Niños Ricardo Gutiérrez,

Buenos Aires, Argentina

M. de Lourdes Figuerola $(\varangle) \cdot$ O. Bruera

Hospital de Clínicas José de San Martín, Unidad de Cefaleas,

Buenos Aires, Argentina

e-mail: mfiguerola@intramed.net

M. J. Pozzo

Servicio de Endocrinología, Hospital Alemán,

Buenos Aires, Argentina

J. Leston

Unidad de Cefaleas, FLENI, Buenos Aires, Argentina ipsilateral autonomic manifestations [3]. It is among the rarest headache syndromes.

Several patients with secondary SUNCT syndromes have been reported since 1991 . They were associated with cerebellopontine angle MAV, parapontine cavernous angioma, dorsolateral brainstem infarction, HIV infection, basilar impression, craniosynostosis, and hypophyseal tumors [4].

Treatments-including methysergide, lithium, propanolol, amitriptyline, carbamazepine and prednisoneusually have poor or negative results. Recently, some partial improvements have been described with the use of lamotrigine, gabapentin and topiramate [5-8].

We are presenting now two cases absolutely responders to steroid therapy, one of them a SUNCT-like secondary to a prolactinoma and the other primary.

\section{Case 1}

A 50-year-old male patient had his first pain attack 4 years before admission. He described a daily severe pulsating pain over the left supraorbital ridge and orbit, extended to the left temple, associated with prominence of autonomic symptoms such as lacrimation and conjunctival injection. Each individual attack lasted 15-120 s and occurred three to six times per day. Neck and head movements triggered pain attacks. He was prescribed amitriptyline, indomethacin, topiramate, and carbamazepine, which did not ameliorate his pain.

In between, he developed an ipsilateral shoulder pain and was locally infiltered with steroids. After this procedure he remained free of head pain for a month.

He had had a left IV nerve palsy 3 years before which improved spontaneously. At this point neuroimaging was not done because the patient did not accept it. 


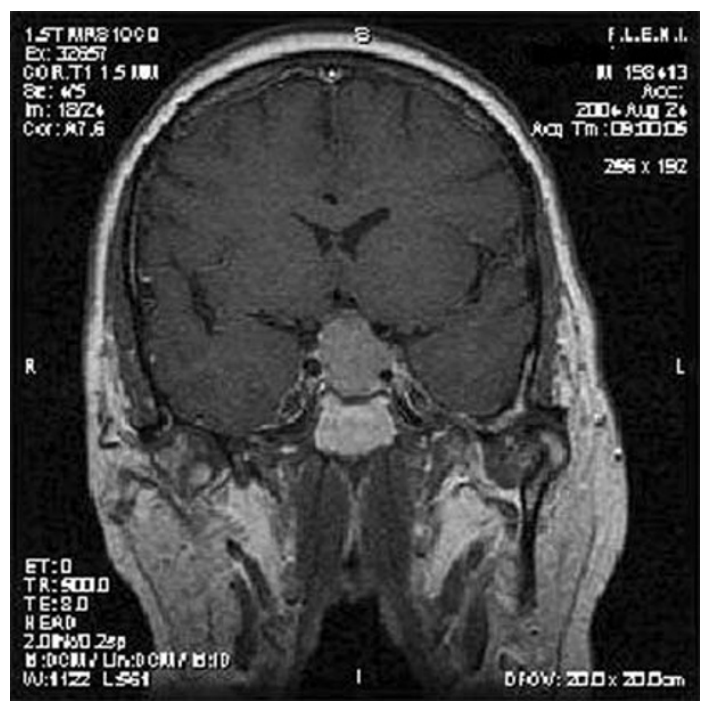

Fig. 1 Macroprolactinoma invading left cavernous sinus at the moment of diagnosis

On admission, clinical examination was unremarkable. Verapamil was prescribed and the pain worsened both in frequency and intensity as described [9]. The following therapeutic choice was prednisone at a dose of $40 \mathrm{mg}$ per day with remission of pain in $24 \mathrm{~h}$. Each time we tried to stop the steroid treatment, recurrence of pain was observed. Finally, a minimal dose $4 \mathrm{mg} / \mathrm{day}$ was sustained with optimal results. The patient was recommended again to

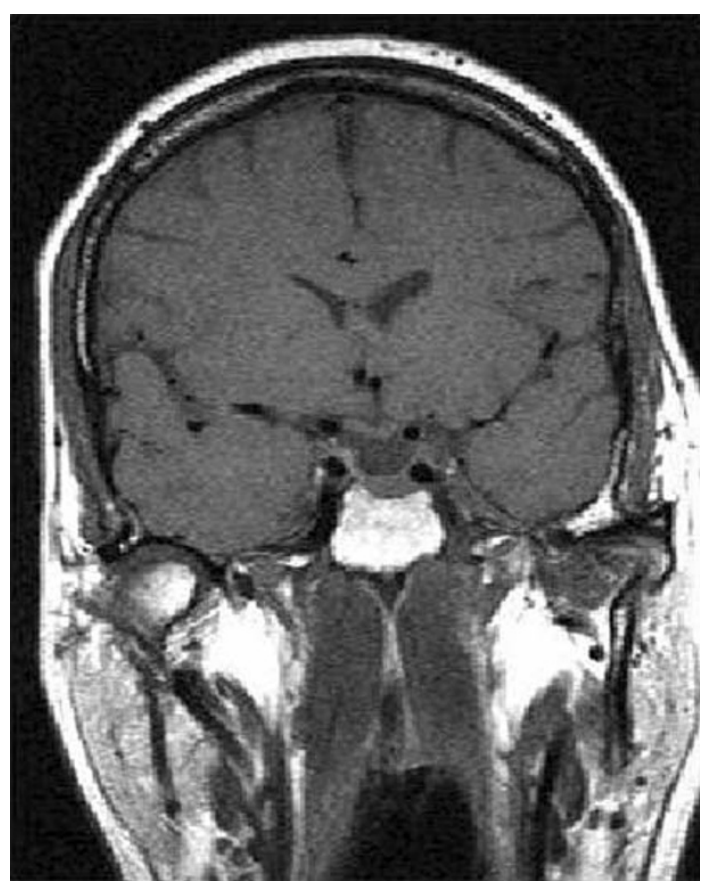

Fig. 2 Reduction of the tumoral mass at 7 months of cabergoline treatment have a neuroimaging study done and this time he accepted. An MRI scan of the brain with and without gadolinium was performed. The study revealed a pituitary adenoma also extended to the left cavernous sinus wall (Fig. 1). No signs or symptoms of the tumor were present. Visual field testing was normal. Serum prolactin levels were markedly elevated $(1,853 \mathrm{ng} / \mathrm{mL}$, normal range $0-20 \mathrm{ng} / \mathrm{mL})$, but testosterone, oestrogen, luteinizing hormone, follicle stimulating hormone, thyroid stimulating hormone, free thyroxin and growth hormone levels were normal. A diagnosis of macroprolactinoma was made and treatment with $2 \mathrm{mg} /$ week of cabergoline was started. A month later prednisone was stopped with no recurrence of headache. Three months later prolactin serum levels were within normal range $(5 \mathrm{ng} / \mathrm{mL})$ and a control MRI after a 6-month follow-up showed a marked reduction of the neoplasm size (Fig. 2). The patient has remained asymptomatic with $1 \mathrm{mg} /$ week of cabergoline (prolactin $2.4 \mathrm{ng} / \mathrm{mL}$ ) since prolactinoma was diagnosed 7 months before.

\section{Case 2}

A 45-year-old male patient had experienced severe left orbital side pulsating pain associated with tearing of the ipsilateral eye and conjunctival injection for 2 months. Potential triggers were strong smells.

Pain attacks lasted 30-90 s and occurred 20-50 times a day. He had no past history of headache and did not recall any trauma to his head. Clinical examination and brain MRI were unremarkable.

SUNCT syndrome was diagnosed and therapeutic options started. The response to indomethacin, lithium, carbamazepine, amitriptyline, and ergotamine was frustrating.

Finally $40 \mathrm{mg} /$ day prednisone was prescribed, and a complete remission of pain was reached after $48 \mathrm{~h}$.

Prednisone dose was decreased slowly until reaching $4 \mathrm{mg} /$ day in 6 weeks. At a dose of $2 \mathrm{mg} / \mathrm{day}$, the pain recurred. For this reason, steroid has been maintained in $4 \mathrm{mg} /$ day. The patient has remained asymptomatic since the steroid drug was installed 15 months ago.

\section{Discussion}

Although SUNCT is a form of primary headache, symptomatic cases have been reported [4]. The treatment of this head pain has been very difficult and frustrating. Partial response to several drugs has been published [5-8].

We are now reporting another two cases with similar headache characteristics, and therapeutic response but with different etiology. Table 1 shows a comparison of clinical characteristics between both patients and IHS criteria. 
Table 1 Comparative clinical findings

\begin{tabular}{llc}
\hline IHS criteria SUNCT & Case 1: secondary SUNCT & Case 2: primary SUNCT \\
\hline $\begin{array}{l}\text { Unilateral orbital, supraorbital or temporal } \\
\text { stabbing or pulsating pain lasting 5-240 } \mathrm{s}\end{array}$ & $\begin{array}{c}\text { Left supraorbital ridge, orbit and temple pain } \\
\text { lasting 15-120 s }\end{array}$ & $\begin{array}{c}\text { Left orbital side pain lasting } \\
30-90 \mathrm{~s}\end{array}$ \\
$\begin{array}{l}\text { Pain is accompanied by ipsilateral conjunctival } \\
\text { injection and lacrimation }\end{array}$ & $\begin{array}{l}\text { Ipsilateral lacrimation and conjunctival injection } \\
\text { Ipsilateral lacrimation and } \\
\text { conjunctival injection }\end{array}$ \\
$\begin{array}{l}\text { Attacks occur with a frequency from } 3 \text { to 200 per } \\
\text { day }\end{array}$ & Three to six times a day & $20-50$ times a day \\
Not attributed to another disorder & Hypophyseal tumor & Normal neuroimaging \\
\hline
\end{tabular}

In the first case (symptomatic), the transient left 4th nerve palsy observed 3 years before, was not studied due to the patient's decision. Probably, the hypophyseal tumor was already present.

When the headache started, different therapeutic drugs were used with disappointing results. When a left shoulder pain was present and a dexamethasone injection was prescribed, the patient was free of head pain for several weeks.

Steroids (first used because of the patient's omalgia and then because of his headache) resolved the pain immediately and recurrence was observed each time they were stopped.

As described previously, verapamil increased pain level. Finally, the patient accepted to be studied and, through laboratory tests and neuroimaging, a macroprolactinoma was diagnosed. Specific treatment with cabergoline was installed with remission of pain in accordance with the reduction of tumor size and serum prolactin levels. Cabergoline therapy allowed to suppress prednisone with no recurrence of SUNCT symptoms.

We can justify the causal relationship considering:

1. Temporal relationship between the prolactinoma and the onset of pain.

2. Side concordance: left cavernous sinus wall infiltration and left side pain.

3. Prompt pain remission with specific therapy for the tumor.

4. A 7-month follow-up.

If we considered that the suprasellar and left extension of the tumor into the cavernous sinus might be responsible for trigeminal activation leading to a homolateral SUNCT syndrome, steroids benefits may be related to an antiinflammatory effect on both the tumor and the cavernous sinus edema. The reduction of the pituitary mass by specific drugs made the anti-inflammatory effect of steroids unnecessary.

Considering that the pathophysiological mechanism of primary SUNCT syndrome remains unknown, in the second case presented, it is more difficult to find a rational explanation to the mechanism of prednisone action. In spite of this, some patients may benefit from prednisone treatment.

Conflict of interest None.

\section{References}

1. Sjaastad O, Russell D, Horven I, et al (1978) Multiple neuralgiform unilateral headache attacks associated with conjunctival injection and appearing in clusters: a nosological problem. In: Proceedings of the Scandinavian Migraine Society 31

2. Sjaastad O, Saunte C, Salvesen R, Fredriksen TA, Seim A, Roe OD et al (1989) Short lasting unilateral neuralgiform headache attacks with conjunctival injection, tearing, sweating and rhinorrhea. Cephalalgia 9:147-156

3. Headache Classification Subcommittee of the International Headache Society (2004) The International Classification of Headache Disorders, 2nd edn. Cephalalgia 24(Suppl 1):44-48

4. Trucco M, Mainardi F, Maggioni F, Badino R, Zanchin G (2004) Chronic paroxysmal hemicrania, hemicrania continua and SUNCT syndrome in association with other pathologies: a review. Cephalalgia 24:173-184

5. Matharu MS, Cohen A, Boes CJ, Goadsby PJ (2003) Short-lasting unilateral neuralgiform headache with conjunctival injection and tearing syndrome: a review. Curr Pain Headache Rep 7:308-318

6. Hunt CH, Dodick DW, Bosch EP (2002) SUNCT responsive to gabapentin. Headache 42:525-526

7. Matharu MS, Boes CJ, Goadsby PJ (2002) SUNCT syndrome: prolonged attacks, refractoriness and response to topiramate. Neurology 58:1307

8. D'Andrea G, Granella F, Ghiotto N, Nappi G (2001) Lamotrigine in the treatment of SUNCT syndrome. Neurology 72:866-871

9. Pareja JA, Kruszewski P, Sjaastad O (1995) SUNCT syndrome: trials of drugs and anesthetic blockades. Headache 35:138-142 